\title{
Sun-protective practices in Iranian seafarers and its psychological predictors
}

\author{
Esmat Heydari, Tahereh Dehdari
}

Department of Health Education and Health Promotion, School of Public Health, Iran University of Medical Sciences, Tehran, Iran

\begin{abstract}
Background: Given the long exposure of seafarers to sunlight and the necessity of recognising determinants of sun-protective practices along with developing educational efforts for the prevention of skin cancer, this study was designed to determine the psychological predictors of sun-protective practices among Iranian seafarers based on protection motivation theory (PMT) variables.

Materials and methods: In this cross-sectional study, 300 seafarers who worked on Ports and Maritime Organisation of Bushehr Port, Iran were selected. PMT and demographic variables were assessed through a 63-item questionnaire. Multiple linear regression (forward method) was used to determine the predictors of adopting sun-protective practices based on PMT variables.

Results: About $11.7 \%$ of the participants always wore a hat with a wide brim of more than $7.5 \mathrm{~cm}$ width, $20 \%$ wore sunglasses while outside under the sun and $12.7 \%$ gloves. Only $13.7 \%$ regularly had their skin checked by a doctor. Behavioural intention, perceived severity, response efficacy and response costs explained $41 \%$ of the variance of adopting sun-protective practices among the seafarers $\left(R^{2}=0.41\right.$, $F=11.89, p<0.001$ ).

Conclusions: The finding explores factors affecting sun protective behaviours among Iranian seafarers. Seafarers with a high level of perceived severity, more response efficacy, more intention for performing behaviour, and fewer response costs were most likely to be regularly engaged in sun protective behaviours.
\end{abstract}

(Int Marit Health 2018; 69, 3: 201-206)

Key words: seafarer, protection motivation theory, skin cancer, sun-protective practices, Iran

\section{INTRODUCTION}

Solar ultraviolet (UV) exposure is the most important environmental risk factor for the development of skin cancer and other illnesses such as solar retinopathy [1, 2]. Some people such as seafarers working outdoors and on decks of vessels have excessive exposure to sunlight. Therefore, the risk of developing skin cancer may increase among them, especially in the uncovered skin such as head [3, 4]. Epidemiological studies have approved that risk of cutaneous squamous cell carcinoma increases 1.70 to 2.22 in individuals with occupational UV exposure than individuals without occupational UV exposure [5]. To the best of our knowledge, the prevalence of skin cancer among seafarers has not been yet considered. In a survey, Burke et al. [6] reported that $9 \%$ of North Carolina commercial fishermen suffered from basal cell carcinoma and $6 \%$ from squamous cell carcinoma.

The need for preventive measures for individuals with high levels of work-related UV light exposure has been highlighted in the literature [5]. Sun protection is of particular importance in the prevention of skin cancer [1]. Avoiding direct exposure to natural UV radiation during times of peak solar intensity (between 11 o'clock in the morning and 3 o'clock in the afternoon), wearing suitable clothing when outdoors, applying sunscreen regularly, keeping in the shade [7] and wearing broad-brimmed hats [8] are habits which can reduce the UV radiation incident on skin for outdoor workers. Avoiding daily exposure $>10$ standard erythema dose could reduce 
sunlight exposure down to $40 \%$ and the risk in developing skin cancer by a factor of 40 [9]. Unfortunately, many seafarers were not aware of the risks of high UV exposure at sea and even a number of them enjoyed intensive sunbathing [10].

Sun safety behaviours in the prevention of skin cancer are difficult to adopt and maintain [11]. Many factors may influence on sun-protective behaviours among general population $[12,13]$. Determinants of the behaviours have been surveyed in occupations with high levels of work-related UV light exposure (e.g. farmers and highway workers) [14, 15]. Additional information regarding theoretical variables that positively or negatively influence on sun protective behaviours among seafarers is required to develop educational efforts for shipboard crews about possible severe health effects due to sun exposure at sea [10]. Theories and models of behaviour change can help to understand the needs of audiences [16]. In addition, these theories may explain why people do or do not engage in a health behaviour $[17,18]$. Given the importance of the theories in developing theory-based efforts in behaviour modification, we used protection motivation theory (PMT) variables to explain sun protective behaviours among Iranian seafarers. PMT was originally introduced by Rogers in 1975 [19] and since then it has been recognised as a suitable theoretical framework for the prediction of behaviour in various issues [20] such as skin cancer-related prevention [14, 21, 22]. PMT posits that protection motivation (i.e. intention to engaging in a behaviour) results from two appraisal processes which are a positive function of the perceptions of perceived severity (beliefs about the severity of the consequences of a health problem), perceived vulnerability (beliefs about personal susceptibility and the likelihood of experiencing a health problem), response efficacy (the belief that the recommended behaviour will be effective in reducing the threat) and self-efficacy (the belief that one is capable of performing the recommended behaviour) as well as a negative function of perceptions of the perceived rewards of associated with not performing the recommended behaviour and the response costs (or barriers) of performing the recommended behaviour [19].

Given the high exposure of seafarers to solar UV radiation [23], the necessity of multiple sun protective behaviours in this group and the lack of studies about acceptance of skin cancer risk-reduction practices among them, present study was designed to identify the predictors of sun protective practices among a group of Iranian seafarers based on PMT variables.

\section{MATERIALS AND METHODS}

\section{DESIGN AND SAMPLE}

This cross-sectional study was done between April and June 2017 in Bushehr port, Iran. In the study, 300 Iranian seafarers were selected by random sampling method. The inclusion criteria for the study were being seafarer at least one year and not having skin cancer or other skin diseases. The native language of the participants was Persian. All of the seafarers were informed about the study and a written consent was obtained from each.

\section{STUDY INSTRUMENTS AND MEASURES}

Protection motivation theory variables were measured through a questionnaire designed and validated by Morowatisharifabad et al. [22] for assessing the PMT variables in terms of adopting sun-protective behaviours for prevention of skin cancer among Iranian farmers. In the 63-item tool, 8 items were used to measure the perceived vulnerability (e.g. "I am unlikely to develop skin cancer in the future"), 7 items for perceived severity (e.g. "If I were to develop skin cancer I would suffer a lot of pain and problems"), 5 items for fear (e.g. "I'm afraid of thinking about skin cancer"), 9 items for response costs (e.g. "Sunglasses are expensive"), 5 items for response efficacy (e.g. "If I wear sunglasses while outside under the sun I would lessen my chance of developing skin cancer"), 4 items for perceived rewards (e.g. "I feel good when I am in the sun"), 10 items for self-efficacy (e.g. "I feel confident in my ability to use sunscreen consistently before I go outside"), 7 items for intention (e.g. "I intend to wear a hat with a wide brim while outside under the sun") and 8 items for sun-protective practices (e.g. "Do you wear gloves when you are in the sun?"). The demographic and PMT variables of the questionnaires were completed by the study participants in 15 to 20 minutes.

\section{STATISTICAL ANALYSIS}

Normality of the gathered data was measured and approved by Kolmogorov-Smirnov test. Spearman correlation test was used to assess the relationship between adopting sun-protective practices and qualitative demographic variables (e.g. marital status). Pearson correlations were also used to examine the relationship between adopting sun-protective practices and quantitative demographic variables (e.g. age). Multiple linear regression (forward method) was used to identify demographic and PMT variables that were associated with adopting sun-protective practices in the participants. The data were analysed using SPSS Statistics (version 24.0, SPSS, Inc., Chicago, IL, USA). P $<0.05$ was considered as statistically significant.

\section{FINDINGS}

Demographic characteristics of the participants are shown in Table 1. Results showed that there were no significant correlation between the mean score of adopting sun-protective practices and demographic variables (except for the family size and history of sunburn) (Table 1). Signifi- 
Table 1. Demographic characteristics of Iranian seafarers $(n=300)$

\begin{tabular}{|c|c|c|c|c|c|}
\hline Variables & & $n$ & $\%$ & Mean \pm SD & $\mathbf{P}^{\#}$ \\
\hline \multirow[t]{4}{*}{ Age } & Under 30 years old & 58 & $19.3 \%$ & $41.39 \pm 11.85$ & 0.51 \\
\hline & $30-49$ & 165 & $55 \%$ & & \\
\hline & $50-59$ & 53 & $17.6 \%$ & & \\
\hline & Over 60 years old & 24 & $8 \%$ & & \\
\hline \multirow[t]{3}{*}{ Marital status } & Single & 60 & $20 \%$ & & 0.24 \\
\hline & Married & 239 & $79.7 \%$ & & \\
\hline & Widowed & 1 & $0.3 \%$ & & \\
\hline \multirow[t]{2}{*}{ Educational level } & $\leq 12$ & 213 & $71 \%$ & & 0.47 \\
\hline & $>12$ & 87 & $29 \%$ & & \\
\hline \multirow[t]{2}{*}{ History of sunburn } & Yes & 94 & $31.3 \%$ & & $0.007^{*}$ \\
\hline & No & 206 & $68.7 \%$ & & \\
\hline Family size & & & & $6.86 \pm 2.87$ & $0.03^{*}$ \\
\hline
\end{tabular}

\#The results of correlation between demographic variables and the mean score of adopting sun-protective practices, ${ }^{*} p<0.05$ significant; SD - standard deviation

Table 2. Correlation among protection motivation theory variables in the study sample $(n=300) ;{ }^{*}<0.05$ significant

\begin{tabular}{|c|c|c|c|c|c|c|c|c|c|}
\hline Variables & 1 & 2 & 3 & 4 & 5 & 6 & 7 & 8 & 9 \\
\hline 1. Sun-protective behaviours & 1 & & & & & & & & \\
\hline 2. Perceived vulnerability & $0.18 *$ & 1 & & & & & & & \\
\hline 3. Perceived severity & $-0.09 *$ & $0.22 *$ & 1 & & & & & & \\
\hline 4. Perceived self-efficacy & $0.18^{*}$ & $0.20 *$ & $0.36^{*}$ & 1 & & & & & \\
\hline 5. Response costs & $-0.31^{*}$ & $-0.12^{*}$ & 0.07 & 0.06 & 1 & & & & \\
\hline 6. Response efficacy & $0.17^{*}$ & $0.28^{*}$ & $0.30 *$ & $0.42 *$ & $0.22 *$ & 1 & & & \\
\hline 7. Perceived rewards & -0.04 & -0.09 & -0.11 & $0.19 *$ & $0.32 *$ & $0.14 *$ & 1 & & \\
\hline 8. Intention & $0.57 *$ & $0.31 *$ & 0.001 & $0.12 *$ & $-0.34 *$ & 0.07 & $-0.17 *$ & 1 & \\
\hline 9. Fear & $0.04 *$ & 0.05 & 0.03 & 0.04 & -0.04 & -0.01 & 0.03 & -0.02 & 1 \\
\hline
\end{tabular}

Table 3. Multiple linear regression (forward method) of Iranian seafarers reported adopting sun-protective practices regressed onto protection motivation theory $(\mathrm{PMT})$ variables $(\mathrm{n}=300)$

\begin{tabular}{|c|c|c|c|c|c|}
\hline Variables & $\mathbf{R}^{2}$ & B & SE & Beta & $\mathbf{P}$ \\
\hline Adopting sun-protective practices onto PMT variables & 0.41 & & & & \\
\hline Constant(a) & & 12.10 & 4.22 & - & $0.004^{*}$ \\
\hline Perceived severity & & -0.27 & 0.09 & -0.15 & $0.003^{*}$ \\
\hline Response costs & & -0.18 & 0.04 & -0.20 & $<0.0001^{*}$ \\
\hline Response efficacy & & 0.30 & 0.09 & 0.18 & $0.001^{*}$ \\
\hline Intention & & 0.56 & 0.06 & 0.48 & $<0.0001 *$ \\
\hline
\end{tabular}

cant correlations were observed between all PMT variables (except for perceived rewards) and adopting sun-protective practices. Correlation between PMT variables is shown in Table 2. Multiple linear regression (forward method) revealed that PMT and demographic variables, perceived severity, response costs, response efficacy and behavioural intention explained $41 \%$ of the variance of adopting sun-protective practices among the participants (Table 3 ). The frequency of adopting sun protective behaviours among the study seafarers is shown in Table 4 and Figure 1. 
Table 4. Frequency of adopting sun-protective practices among Iranian seafarers $(n=300)$

\begin{tabular}{|c|c|c|c|c|}
\hline Sun-protective practices & Never & Sometimes & Often & Always \\
\hline $\begin{array}{l}\text { Do you apply sunscreen with sun protection factor of }>15 \\
\text { before you go outside? }\end{array}$ & $138(46 \%)$ & $105(35 \%)$ & $27(9 \%)$ & $30(10 \%)$ \\
\hline $\begin{array}{l}\text { Do you wear a hat with a wide brim of more than } 7.5 \mathrm{~cm} \text { width } \\
\text { when you outside under the sun? }\end{array}$ & $58(19.3 \%)$ & $154(51.3)$ & $52(17.3 \%)$ & $35(11.7 \%)$ \\
\hline Do you wear gloves when you are outside? & $97(32.3 \%)$ & $128(42.7 \%)$ & $37(12.3 \%)$ & $38(12.7 \%)$ \\
\hline Do you use sunglasses when you are outside under the sun? & $44(14.7 \%)$ & $139(46.3 \%)$ & $57(19 \%)$ & $60(20 \%)$ \\
\hline $\begin{array}{l}\text { Do you wear long-sleeve shirt and long pant and/or skirt } \\
\text { when you are outdoor? }\end{array}$ & $28(9.3 \%)$ & $139(46.3 \%)$ & $71(23.7 \%)$ & $62(20.7 \%)$ \\
\hline $\begin{array}{l}\text { Do you have outdoor activities during early hours of the morning } \\
\text { and/or afternoon? }\end{array}$ & $43(14.3 \%)$ & $139(46.3 \%)$ & $71(23.7 \%)$ & $47(15.7 \%)$ \\
\hline $\begin{array}{l}\text { Do you immediately see a doctor when you find something } \\
\text { unusual on your skin changes? }\end{array}$ & $79(26.3 \%)$ & $104(34.7 \%)$ & $49(16.3 \%)$ & $68(22.7 \%)$ \\
\hline Do you have your skin checked by a doctor on a regular basis? & $148(49.3 \%)$ & $83(27.7 \%)$ & 28 (9.3\%) & 41 (13.7\%) \\
\hline
\end{tabular}

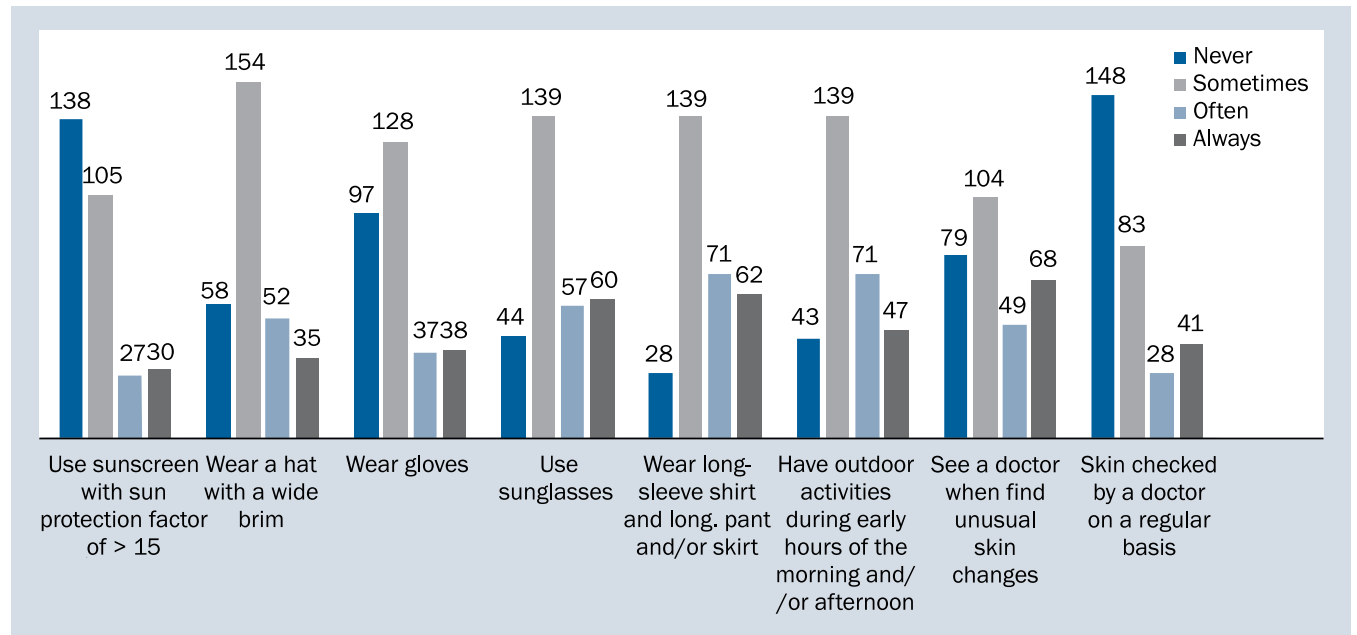

Figure 1. Frequency of adopting sun-protective practices among Iranian seafarers $(n=300)$

\section{DISCUSSION}

The results supported the role of perceived severity in adopting sun protective behaviours among Iranian seafarers. Kasparian et al. [13] in a systematic review explained that perceived risk of skin cancer was one of the factors influencing adherence to sun protective and screening recommendations. Craciun et al. [24] found that risk perception operated as a moderator in the intention-planning-sunscreen. According to PMT assumptions, protection motivation results from two appraisal processes. One of the processes is that individuals' perception of the severity of, and their vulnerability to a threat should outweigh the perceived rewards related to maladaptive responses [19]. It's worth mentioning that the more maladaptive strategy simultaneously reduced individuals' fear of the exposed threat and strengthened their intentions to perform the maladaptive responses (such as denial and avoidance of the threat) [25]. In the present study, perceived rewards were not significant predictor of the target behaviour among the participants. It can be concluded that seafarers who more protect themselves against the sunlight, had higher threat appraisal about skin cancer. In fact, health professionals can develop persuasive messages to meet perceived severity to increase skin cancer preventive behaviours among the Iranian seafarers.

With respect to PMT assumptions, the second appraisal process for eliciting the protection motivation is that individuals' perception of the response efficacy of, and self-efficacy should outweigh the response costs of recommended behaviour [19]. The results of the present study showed that response costs and response efficacy were both significant predictors of adopting sun protective practices among the 
study participants. What is notable here is that in contrast to previous studies [14] self-efficacy had not significant effect on the seafarers' behaviour regarding the sun protection. This finding is consistent with Rooshanpour Dehbari et al. [21]. They demonstrated that among PMT variables, only intention and response costs variables could predict the sun-protective practices among Iranian female college students. In their study, response efficacy and self-efficacy were significant predictors of participants' intention to perform sun-protective practices [21]. Overall, the results showed the degree of response costs was more effective than response efficacy and self-efficacy for engaging in skin cancer prevention among the seafarers. Seafarers with low response costs were more likely to have high levels of performing sun protection behaviour. Since decrease in response costs may facilitate performing preventive behaviours [26], while developing interventions, more attention to response costs and educating the methods to overcome them may foster the probability of the adaptive coping and performing sun protective behaviours among Iranian seafarers.

Similar to previous studies [21], in the present study, behavioural intention was also identified as one of the predictors of sun-protective behaviour among the seafarers. Those seafarers who had higher intention for protecting themselves against sunlight possibly used more sun-protective strategies than those with less intention. Although intention to change behaviour has been introduced as the best predictor of actual change, literature shows that all individuals who intended to adopt sun protective behaviour, did not perform it [11]. This finding can be explained due to factors (e.g. intrinsic and extrinsic) and unforeseen barriers which may influence the process of translating intention into action. These postintentional mediators to overcome the intention-behaviour gap should be identified to inhibit maladaptive responses in terms of skin cancer-related prevention among the Iranian seafarers.

Findings of the study showed that the participants' performance above all considered sun protective behaviour (Table 4 ) to be poor (<20\%). For example, only $11.7 \%$, $12.7 \%$ and $20 \%$ of the participants always used a hat with a brim, gloves and sunglasses in the exposure of the sunlight, respectively. In fact, only ten per cent of the participants in this study applied sunscreen with sun protection factor of $>15$ before they go outside and $13.7 \%$ of them had their skin checked regularly by a doctor. These findings are consistent with Rooshanpour Dehbari et al. [21] and Babazadeh et al. [14]. Also, Oldenburg et al. [10] reported that $55.7 \%$ of the seafarers used sunscreens during sunlight exposure at sea. Kasparian et al. [13] in a systematic review reported that sunscreen use varied across studies, ranging from $7 \%$ to $90 \%$. Also, the prevalence of annual clinical skin examination ranges from $8 \%$ to $21 \%$. Only $23 \%$ and $61 \%$ of individuals were engaged in self-examination of their skin at least once per year. They revealed that a large proportion of the population engaged in suboptimal levels of sun protection and a number of factors can influence it [13]. In a study by Knight et al. [27] it was shown that despite adequate knowledge of the risk associated with UV exposure, $47 \%$ of young adults had used tanning lambs during the preceding 12 months. Identifying mediator factors between knowledge and behaviour can help to develop appropriate efforts in this field.

Although this study was the first research which highlighted the application of PMT variables in predicting sun-protective behaviours among a sample of Iranian seafarers, it suffered from some limitations, too. Data was collected among seafarers who were working at the Port. Thus, the findings cannot be generalised to seafarers in other parts of Iran or other occupation groups. Similar studies on other occupation groups such as fishermen in Iran are suggested.

\section{CONCLUSIONS}

To conclude, seafarers with more intention, response efficacy and perceived severity and less response costs were more likely to protect themselves against the sunlight. Practitioners should also take into account these significant variables in developing theory-based interventions to increase the preventative behaviour for the control of skin cancer among the seafarers.

\section{ACKNOWLEDGEMENTS}

The authors would like to thank seafarers in Genaveh Port for participation in the study.

\section{ETHICAL APPROVE AND CONSENT TO PARTICIPATE}

Ethical approval for the study was provided by Ethics Committee of Iran University of Medical Sciences

\section{FUNDING}

This study was supported by Iran University of Medical Sciences.

\section{CONFLICT OF INTEREST}

The authors declare that they have no conflict of interest.

\section{REFERENCES}

1. Reichrath J. The challenge resulting from positive and negative effects of sunlight: how much solar UV exposure is appropriate to balance between risks of vitamin $D$ deficiency and skin cancer? Prog Biophys Mol Biol. 2006; 92(1): 9-16, doi: 10.1016/j.pbiomolbio.2006.02.010, indexed in Pubmed: 16603232.

2. Cabrera PR, Dorta LC, Hernández MG. Bilateral solar retinopathy. Autofluorescence and optical coherence tomography. Archivos de la Sociedad Española de Oftalmología (English Edition). 2016; 91(8): 391-396, doi: 10.1016/j.oftale.2016.04.026. 
3. Feister U, Meyer G, Kirst U. Solar UV exposure of seafarers along subtropical and tropical shipping routes. Photochem Photobiol. 2013; 89(6): 1497-1506, doi: 10.1111/php.12144, indexed in Pubmed: 23875870.

4. Carter T, Karlshoej K. The design of health promotion strategies for seafarers. Int Marit Health. 2017; 68(2): 102-107, doi: 10.5603/ IMH.2017.0019, indexed in Pubmed: 28660613.

5. Schmitt J, Seidler A, Diepgen TL, et al. Occupational ultraviolet light exposure increases the risk for the development of cutaneous squamous cell carcinoma: a systematic review and meta-analysis. Br J Dermatol. 2011; 164(2): 291-307, doi: 10.1111/j.13652133.2010.10118.x, indexed in Pubmed: 21054335.

6. Burke WA, Griffith DC, Scott CM, et al. Skin problems related to the occupation of commercial fishing in North Carolina. N C Med J. 2006; 67(4): 260-265, indexed in Pubmed: 17066654.

7. Fry A, Verne J. Preventing skin cancer. BMJ. 2003; 326(7381): 114-115, doi: 10.1136/bmj.326.7381.114, indexed in Pubmed: 12531819 .

8. Gambichler T, Laperre J, Hoffmann K. The European standard for sun-protective clothing: EN 13758. J Eur Acad Dermatol Venereol. 2006; 20(2): 125-130, doi: 10.1111/j.1468-3083.2006.01401.x, indexed in Pubmed: 16441617.

9. Schmalwieser AW, Cabaj A, Schauberger G, et al. Facial solar UV exposure of Austrian farmers during occupation. Photochem Photobiol. 2010; 86(6): 1404-1413, doi: 10.1111/j.17511097.2010.00812.x, indexed in Pubmed: 21039574.

10. Oldenburg M, Kuechmeister B, Ohnemus U, et al. Extrinsic skin ageing symptoms in seafarers subject to high work-related exposure to UV radiation. Eur J Dermatol. 2013; 23(5): 663-670, doi: 10.1684/ ejd.2013.2142, indexed in Pubmed: 24135214.

11. Craciun C, Schüz N, Lippke S, et al. A mediator model of sunscreen use: a longitudinal analysis of social-cognitive predictors and mediators. Int J Behav Med. 2012; 19(1): 65-72, doi: 10.1007/ s12529-011-9153-x, indexed in Pubmed: 21394444.

12. Dadlani C, Orlow SJ. Planning for a brighter future: a review of sun protection and barriers to behavioral change in children and adolescents. Dermatol Online J. 2008; 14(9): 1, indexed in Pubmed: 19061583.

13. Kasparian NA, McLoone JK, Meiser B. Skin cancer-related prevention and screening behaviors: a review of the literature. J Behav Med. 2009; 32(5): 406-428, doi: 10.1007/s10865-009-9219-2, indexed in Pubmed: 19521760.

14. Babazadeh T, Nadrian H, Banayejeddi M, et al. Determinants of skin cancer preventive behaviors among rural farmers in Iran: an application of protection motivation theory. J Cancer Educ. 2017; 32(3): 604-612, doi: 10.1007/s13187-016-1004-7, indexed in Pubmed: 26922176.
15. Stock ML, Gerrard M, Gibbons FX, et al. Sun protection intervention for highway workers: long-term efficacy of UV photography and skin cancer information on men's protective cognitions and behavior. Ann Behav Med. 2009; 38(3): 225-236, doi: 10.1007/s12160009-9151-2, indexed in Pubmed: 20049658.

16. Spahn JM, Reeves RS, Keim KS, et al. State of the evidence regarding behavior change theories and strategies in nutrition counselling to facilitate health and food behavior change. J Am Diet Assoc. 2010; 110(6): 879-891, doi: 10.1016/j.jada.2010.03.021, indexed in Pubmed: 20497777.

17. Croyle RT. Theory at a glance: application to health promotion and health behaviour. 2nd ed. Washington, DC: United States Department of Health and Human Services, National Cancer Institute 2005.

18. Jackson C. Behavioral science theory and principles for practice in health education. Health Edu Res. 1997; 12(1): 143-150, doi: 10.1093/her/12.1.143.

19. Conner M, Norman P. Predicting health behaviour: research and practice with social cognition models. Second edition. Open University Press. 2005: 81-126.

20. Milne S, Sheeran P, Orbell S. Prediction and intervention in health-related behavior: a meta-analytic review of protection motivation theory. J Appl Soc Psychol. 2000; 30(1): 106-143, doi: 10.1111/j.15591816.2000.tb02308.x.

21. Rooshanpour Dehbari S, Dehdari T, Dehdari L, et al. Predictors of sun-protective practices among Iranian female college students: application of protection motivation theory. Asian Pac J Cancer Prev. 2015; 16(15): 6477-6480, doi: 10.7314/арjcp.2015.16.15.6477.

22. Morowatisharifabad M, Bonyadi F, EbrahimzadehArdakani M, et al. Study of sun protective behaviours for skin cancer prevention and its barriers among Kazeroon farmers. TB. 2015; 13(5): 68-82. (in Persian).

23. Lampel HP. Skin cancer screening in occupational medicine. University of Pittsburgh. 2005.

24. Craciun C, Schüz N, Lippke S, et al. Risk perception moderates how intentions are translated into sunscreen use. J Behav Med. 2010; 33(5): 392-398, doi: 10.1007/s10865-010-9269-5, indexed in Pubmed: 20549325.

25. Rippetoe PA, Rogers RW. Effects of components of protection-motivation theory on adaptive and maladaptive coping with a health threat. J Pers Soc Psychol. 1987; 52(3): 596-604, indexed in Pubmed: 3572727.

26. Floyds D, Entice-Dunin S, Rogersi R. A meta-analysis of research on protection motivation theory. J Appl Soc Psychol. 2000; 30(2): 407-429, doi: 10.1111/j.1559-1816.2000.tb02323.x.

27. Knight JM, Kirincich AN, Farmer ER, et al. Awareness of the risks of tanning lamps does not influence behavior among college students. Arch Dermatol. 2002; 138(10): 1311-1315, doi: 10.1001/archderm.138.10.1311, indexed in Pubmed: 12374536. 